\title{
Socio-economic determinants affecting the lifestyle of pregnant women
}

Fatemeh Estebsari

* PhD of Health Education \& Promotion, Assistant Professor, Department of Community Health Nursing, School of Nursing \& Midwifery, Shahid Beheshti University of Medical Sciences, Tehran, Iran. (Corresponding Author). Email: fa_estebsari@yahoo.com

Farideh Jalili-Bahabadi

Student Research Committee, Department of Midwifery and Reproductive Health, School of Nursing \& Midwifery, Shahid Beheshti University of Medical Sciences, Tehran, Iran.

Camelia Rohani

Associate Professor, Community Health Nursing Department, School of Nursing and Midwifery, Shahid Beheshti University of Medical Sciences, Tehran, Iran.

Zahra Rahimi Khalifeh Kandi PhD Candidate of Health Education \& Promotion. Department of Health Education, School of Public Health, Iran University of Medical Sciences, Tehran, Iran.

Davoud Mostafaei

PhD in Health Services Management. Shahid Beheshti University of Medical Sciences, Tehran, Iran.

Received: 2020/01/19

Accepted: 2020/06/22

Doi: 10.29252/ijhehp.8.3.261

\section{ABSTRACT}

Background and Objective: Lifestyle is one of the factors influencing health. The lifestyle of pregnant women undergoes many changes during pregnancy and childbirth. The aim of this study was to identify socio-economic determinants affecting the lifestyle of pregnant women

Materials and Methods: This was a descriptive-analytic study carried out on 300 pregnant women in Yazd who were selected by random sampling. Data collection tools include demographic information questionnaire and HPLPII profile. Data were entered into SPSS 18 . Descriptive and analytical statistics were used for analysis. Significant level was $<0.05$.

Results: The mean score of health promoting behaviors of pregnant women was $154.9 \pm 2.2$. The highest mean score belonged to the spiritual growth dimension $(30 \pm 3.6)$ and the lowest mean belonged to the physical activity dimension (17.8 \pm 10.2 ). According to the results, there was a significant relationship between age, education and employment of pregnant women and education of spouse with health promoting behaviors $(P<0.05)$.

Conclusion: Based on the results of the present study, demographic, social and economic variables have an effect on the lifestyle of pregnant women and attention to it should be considered as a priority in planning related to providing health services and macro-national policies to improve maternal and children health should be considered.

Keywords: Lifestyle, Health Promoting Behaviors, Social Variables, Economic Variables, Pregnant Women

Paper Type: Research Article.

Citation (Vancouver): Estebsari F, Jalili-Bahabadi F, Rohani C, Rahimi Khalifeh Kandi Z, Mostafaei D. Socio-economic determinants affecting the lifestyle of pregnant women. Iran J Health Educ Health Promot. Spring 2020;8(3): 261-271. [Persian]x

Citation (APA): Estebsari F., Jalili-Bahabadi F., Rohani C., Rahimi Khalifeh Kandi Z., Mostafaei D. Socio-economic determinants affecting the lifestyle of pregnant women. Iranian Journal of Health Education \& Health Promotion., 8(3), 261-271 . [Persian] 


\section{تعيينكنندههاى اجتماءى - اقتصادى مؤثر بر سبك زندكى زنان باردار}

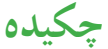

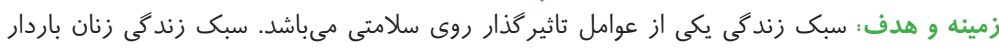

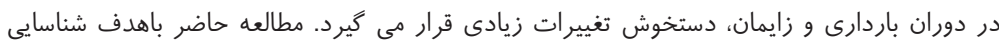

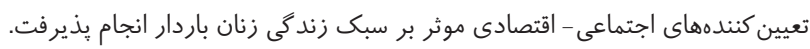

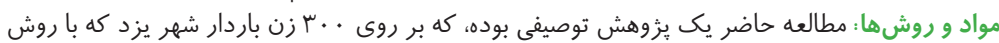

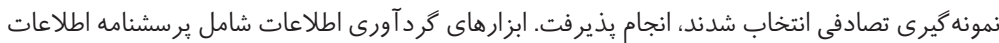

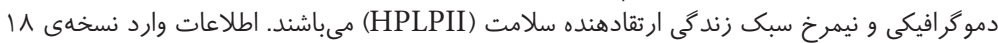
SPSS نظر كرفته شد.

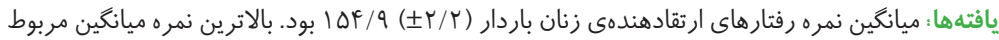

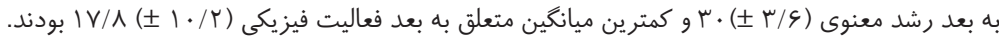

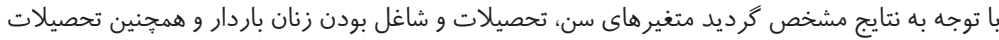

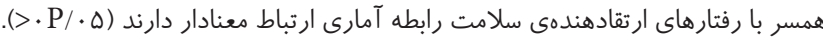

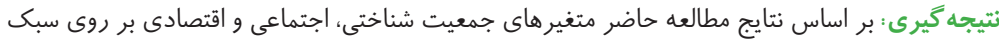

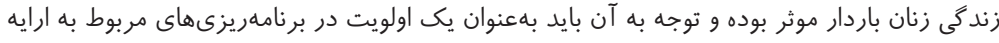

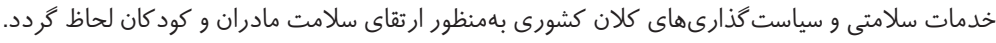

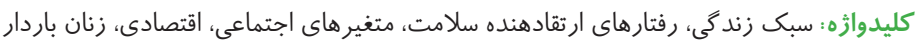

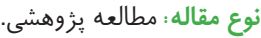

4 استناد (ونكوور): استبصارى ف، جليلى بهابادى ف، روحانى ك، رحيمى خليفه كندى ز، مصطفايى د.

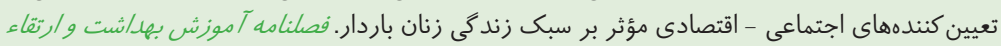

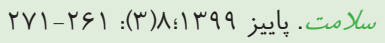

4 استناد (APA): استبصارى، فاطمه؛ جليلى بهابادى، فريده؛ روحانى، كامليا؛ رحيمى خليفه كندى، زهراء

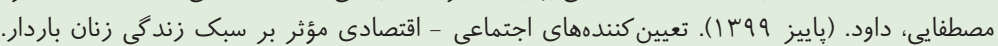

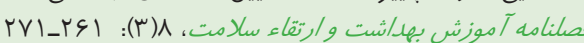

فاطمه استبصارى * مكتراى آموزش بهداشت و ارتقاى سلامت، استاديار

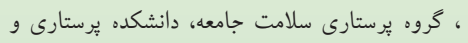

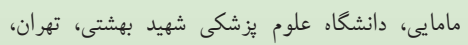
fa_estebsari@yahoo.com

$$
\text { ايران.( نويسنده مسئول): }
$$

$$
\text { فريده جليلى بهابادى }
$$

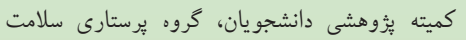

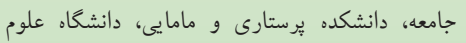
يزشكى شهيد بهشتى، تهران، ايران

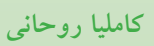
دكتراى يرستارى، دانشيار، گروه يُرستارى سلامت

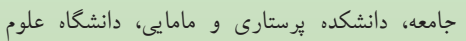

$$
\text { يزشكى شهيد بهشتى، تهران، ايران }
$$

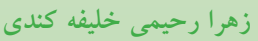

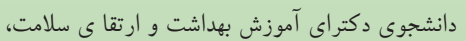

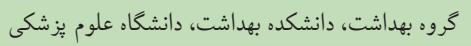
ايران، تهران، ايران داود مصطفايى دكتراى مديريت خدمات بهداشتى، دانشكاء علوم يزشكى شهيد بهشتى، تهران، ايران

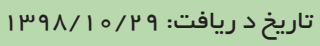

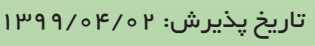


دارد (II) به كونهاى كه سبك زندكى ناسالم، خطر زايمان زودرس

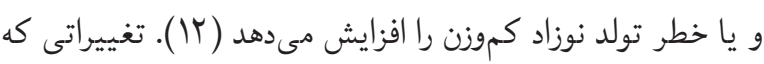

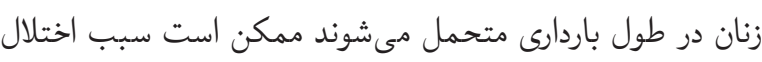
در انجام برخى حركات و فعاليتهاي روزمره كردد (سآ). لذا نياز

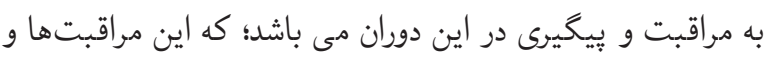

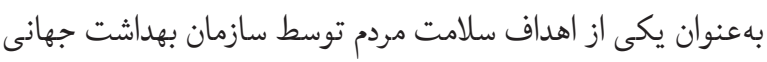

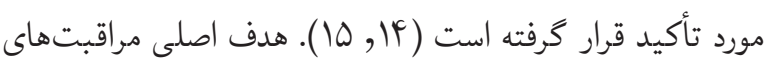

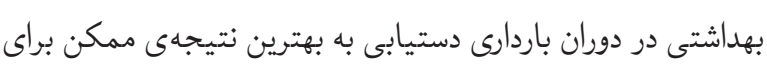

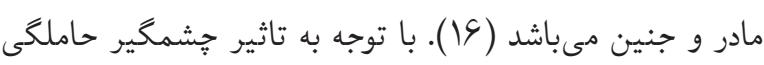

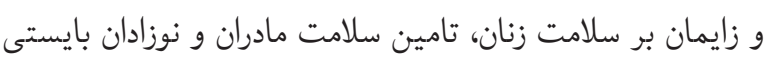
يكى از اولويت هاى خدمات سلامتى به شمار آيد (IV) . براى فهم

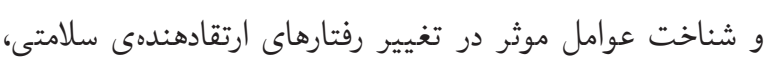

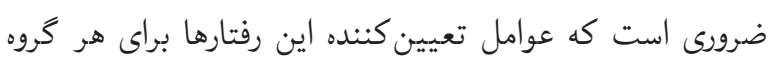

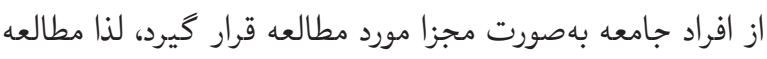
حاضر باهدف شناسايى تعيين كنندهاى اجتماعى- اقتصادى موثر

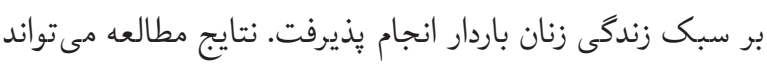

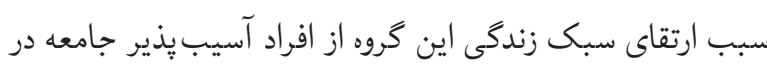
جهت كسب زندگى باكيفيت تر دوران باردارى و بِ إن از آن كَردد.

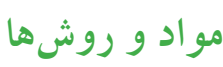

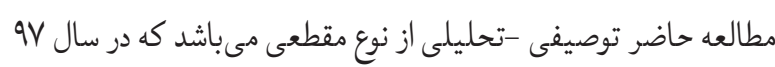

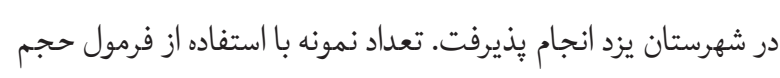

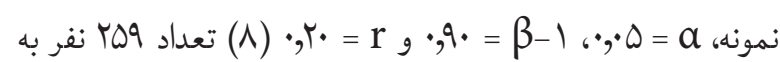

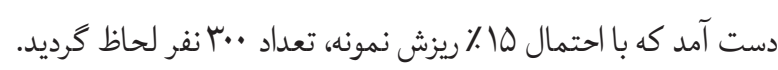

$$
n \geq\left[\frac{\left(Z_{1-\alpha / 2}+Z_{1-\beta}\right)}{0.5 \times \ln [(1+r) /(1-r)]}\right]^{2}+3
$$

در ابتدا از بين f أمر اكز بهداشتى تحت يوشش شبكه بهداشت

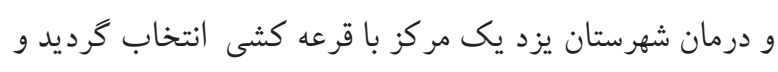

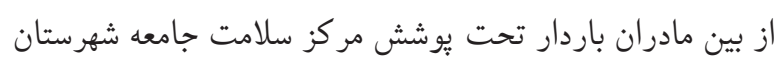
كه داراى معيارهاى ورود به مطالعه بودند، از طريق نمونه كيرى باري
در دنياى امروزى، سبك زندگى بهعنوان يكى از عوامل مهم تاثير

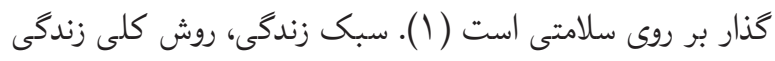

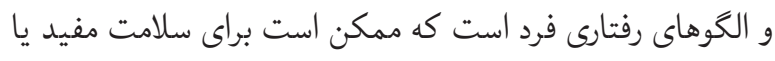

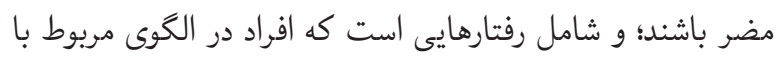

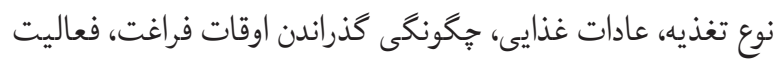

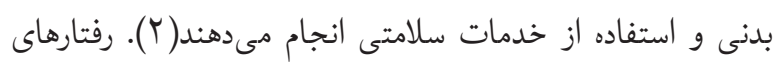

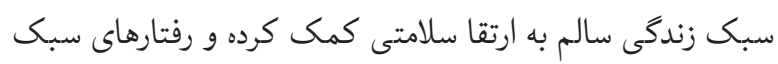

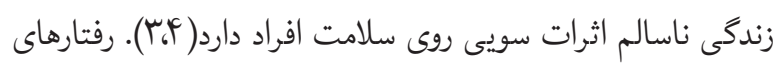

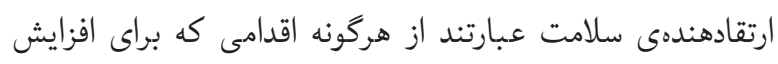

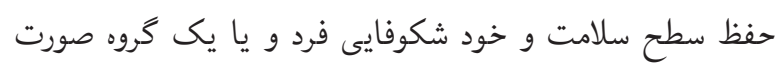

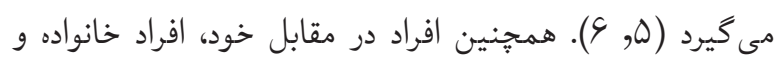

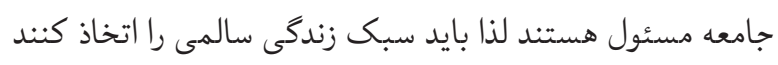

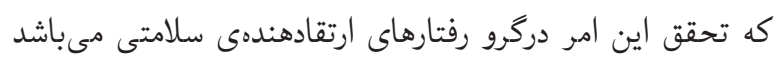

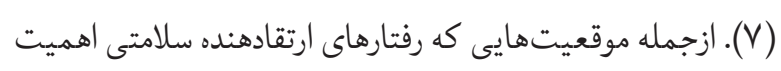

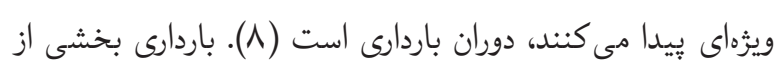

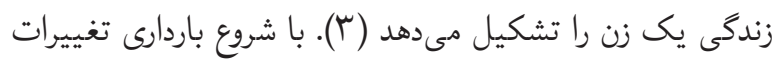

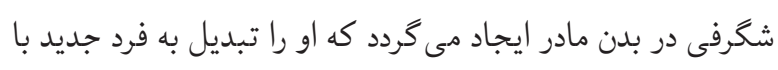

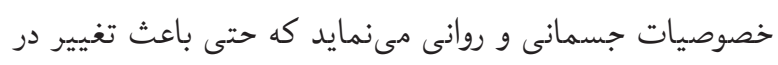
رفتارهاى سلامتى و سبك زندگى وى مي گَردد (9). دوران باردارى

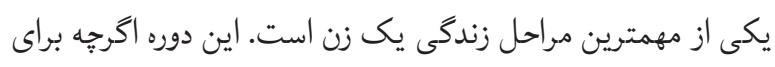

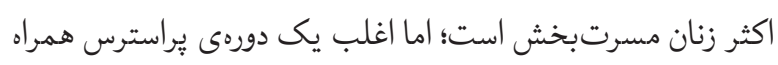

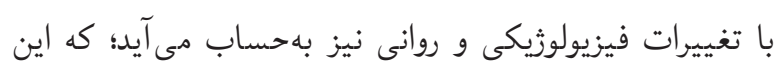

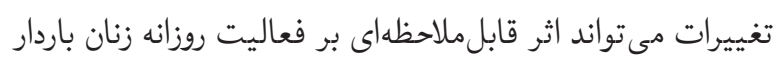

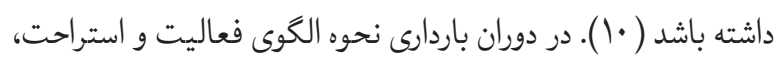

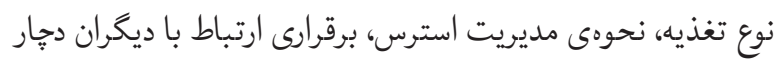

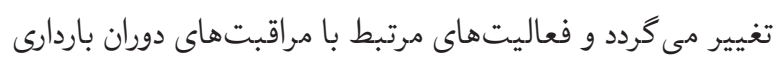

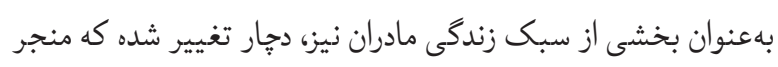

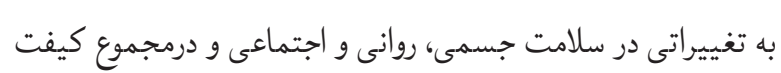

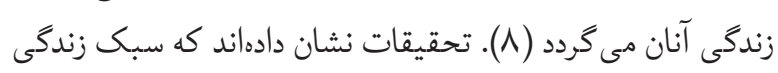
دوران بارداري، اثرات ماندكار طولانىمدتى روى سلامت مادر و و كودى 
ابزار در مطالعات گوناكون تاييد شده است (1), 19) در ايران

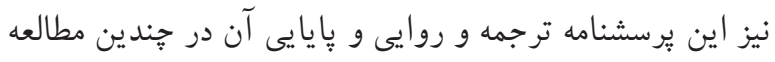
مورد تاييد قراركرفته است (·r). بهمنظور تعيين اعتبار يرسشنامهها در اين يُزوهش، از روش

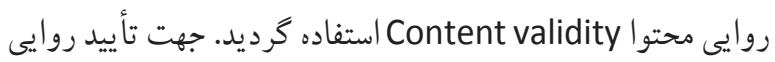

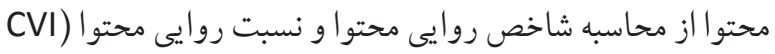
Content Validity استفاده مىشود. نسبت روايى محتوى مونى (\&CVR Ratio, CVR محتوى Validity Index, CVI Content (مر بوط بودن، واضح بودن و ساده بودن هر سوال) را مورد بررسى قرار مى دهد. بهمنظور محاسبه

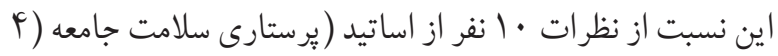
نفر)، متخصص بهداشت مادر و كودى (r نفر) و متخصصان بهداشت

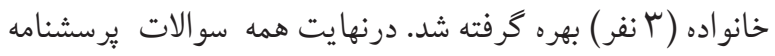

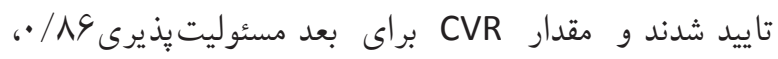

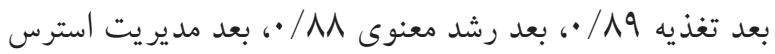

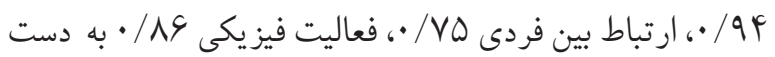

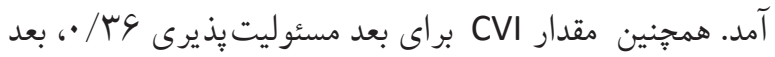

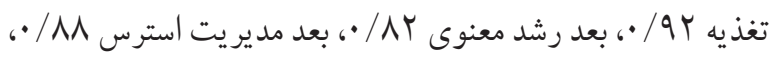

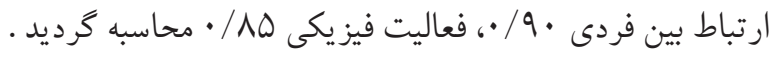

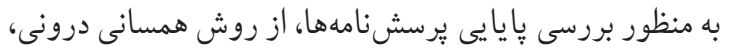

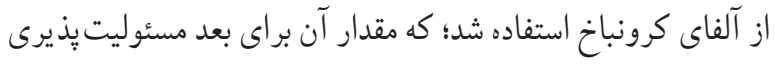

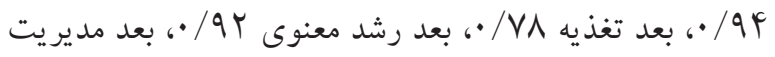

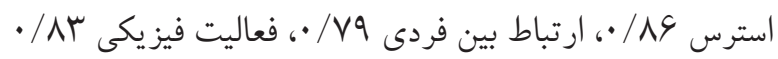

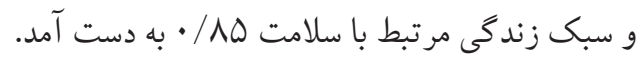
ملاحظات اخلاقى: يُزوهش حاضر مصوب شوراى يُزوهشى دانشكاء

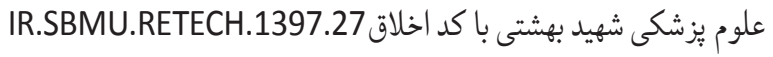

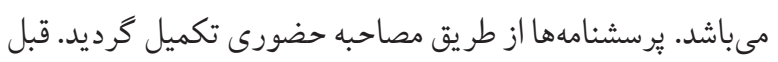

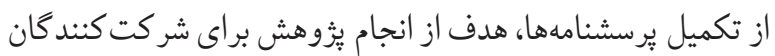

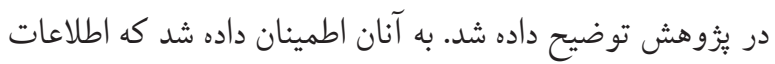

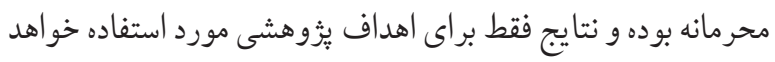

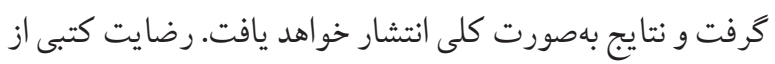

تصادفى (زوج بودن شماره يرونده مركز) شركت كنندها وارد

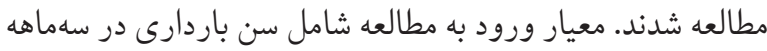

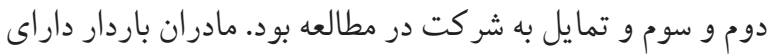

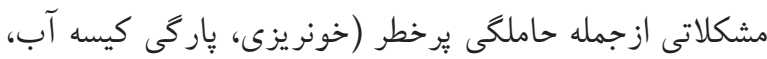
يُره كلاميسى يا اكلاميسى و يا ديابت باردارى با تزريق انسولين) و يا داراى مشكل جسمى و روحى و يا بيمارىهاى زمينهاى مثل

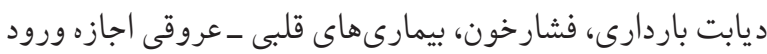

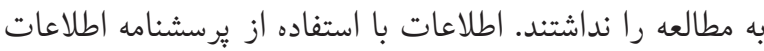

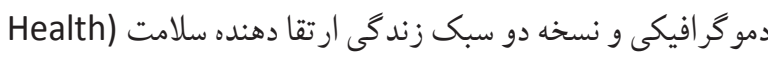
(Promoting Lifestyle Profile II) (HPLPII يرسشنامه اطلاعات دمو گ افيكى: يرسشنامه اطلاعات دمو گر افيكى

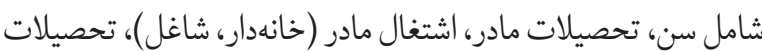
همسر، اشتغال همسر، سن حاملغى، شاخص توده بدنى در دوره باردارى بود. يرسشنامه رفتارهاى ارتقادهنده سلامتى: از نسخه دو سبك تسك زندگى ارتقادهندهى سلامت Health Promoting Lifestyle Pender Profile II (HPLPII است (T (I)، براى سنجش رفتارهاى ارتقادهنده سلامتى استفاده

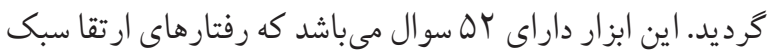

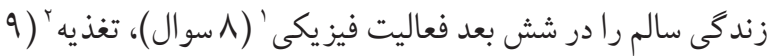

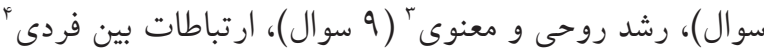

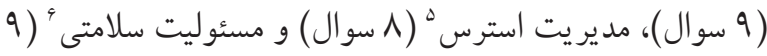
سو ال) مورد ارزيابى قرار مىدهد. اين برسشنامه بر اساس مقياس

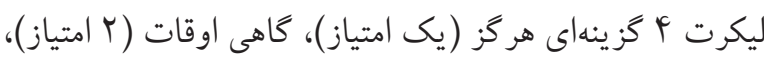

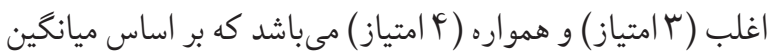
نمره سبك زندگى كل و ميانگين ابعاد محاسبه گرديد. نمره بالاتر،

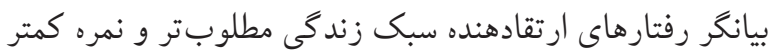

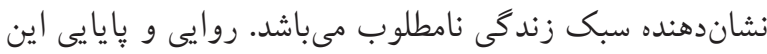


جدول ا: توزيع فراوانى متغيرهاى دموگرافيكى زنان باردار و ارتباط ان با سبك زندگى كل

\begin{tabular}{|c|c|c|c|c|c|}
\hline \multicolumn{6}{|c|}{ سبك زندگى كل } \\
\hline $\mathbf{P}$ & ميانگين (انحراف معيار 土) & $\%$ & فراوانى & & 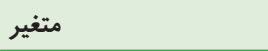 \\
\hline \multirow{4}{*}{ *ै./.r } & $\mid \Delta Y / Y \wedge(Y \Psi / \Delta V)$ & rs & $\vee \wedge$ & كمتر از • r سال & \multirow{4}{*}{ سن } \\
\hline & $\mid \Delta N / V S(Y \mu / Y \mid)$ & $19 / 9$ & $\Delta V$ & ا r تا & \\
\hline & IrN/GS $(r \cdot / r \Delta)$ & $19 / 1$ & $\Delta$. & عץ-• • سال & \\
\hline & $10 F / 90(19 / 91)$ & rN/ & 110 & بيشتر از •ـ سال & \\
\hline \multirow{5}{*}{ 米. $/$ rs } & $\mid \Delta \Lambda / \Delta \Lambda(Y Y / V Y)$ & rV & $\wedge$. & 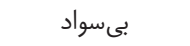 & \multirow{5}{*}{ تحصيلات } \\
\hline & $\mid \& s / 19(V / \Delta \cdot)$ & 1. & r. & ابتدايى & \\
\hline & $\mid \Delta \Delta / \cdot V(Y F / \Lambda F)$ & rt & 90 & راهنمايى & \\
\hline & $\mid \Delta V / F \cdot(r \mu / \varsigma \Delta)$ & $\Delta r$ & Vo & دبير ستان & \\
\hline & $10 \cdot / 1 \cdot(19 / 94)$ & $19 / 1$ & $\Delta$. & دانشگاه و بالاتر & \\
\hline \multirow{2}{*}{$>$ 米米. $/ . .1$} & $1 \Delta \Lambda / \Delta V(r Y / \Lambda \mu)$ & $S V$ & $r \cdot$. & خانهدار & \multirow{2}{*}{ اشتغال } \\
\hline & $\mid F V / \Delta \Delta(19 / .9)$ & 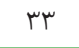 & $1 \cdots$ & 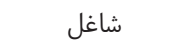 & \\
\hline \multirow{5}{*}{$>* * \cdot . \cdot 1$} & $\mid r s / \Lambda \cdot(r \cdot / \cdot q)$ & $\Lambda / \mu$ & ro & 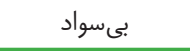 & \multirow{5}{*}{ تحصيلات همسر } \\
\hline & $\mid \digamma \wedge / \cdots(\mid \wedge / \mu \vee)$ & $\Lambda / \mu$ & ro & ابتدايى & \\
\hline & $\mid \Delta r / \wedge r(r \mid / 9 r)$ & $r \cdot$ & 4. & راهنمايى & \\
\hline & $\mid G Y / G \Lambda(Y Y / Y \Delta)$ & $F \mid / V$ & iro & دبير ستان & \\
\hline & $10 \cdot / \Delta \mu(\mid r / \Lambda \varsigma)$ & $r \mid / r$ & 90 & دانشخاه و بالاتر & \\
\hline \multirow{3}{*}{$* \cdot / \cdot \wedge \Delta$} & $|\Delta V / \Lambda|(r q / \cdot r)$ & $\mid N / r$ & $\Delta \Delta$ & 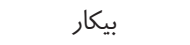 & \multirow{3}{*}{ اشتغال همسر } \\
\hline & $10 \Delta / 4 \&(19 / 94)$ & $G \Lambda / F$ & $r \cdot \Delta$ & شغل آزاد & \\
\hline & $\mid F \wedge / \ldots(r \mid / \wedge \varsigma)$ & $\mid r / \mu$ & f. & كارمند دولت & \\
\hline \multirow{2}{*}{ 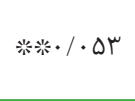 } & $\mid \Delta V / \cdots(r \Delta / \mathcal{F} \mu)$ & $\Delta N / \mathcal{F}$ & IVD & سهماهd دوم & \multirow{2}{*}{ سن حاملىى } \\
\hline & $101 / 98(19 / F \Delta)$ & $F \mid / V$ & Iro & سهماهه سوم & \\
\hline \multirow{4}{*}{$* / 11$. } & $1 \Delta S / \Gamma \Delta(Y \Psi / 9 \Delta)$ & $9 / 1$ & 11 & كمتر از N/D & \multirow{4}{*}{ BMI } \\
\hline & $101 / 1 \cdot(r \mid / \mu F)$ & $r \mu / v$ & VI & $1 N / \Delta-r F / q$ & \\
\hline & $10 \Lambda / 1 \mid(r|/| 9)$ & $r \Delta / q$ & $1 \cdot 1$ & $r \Delta-r q / q$ & \\
\hline & $\mid \Delta S / G S(r / \Delta)$ & $\mu F / \mu$ & $1 \cdot r$ & بيشتر از •r & \\
\hline
\end{tabular}

T-test 橉 ANOVA jow

شر كت كنند كان در ثزوهش دريافت گرديد. مادران باردار باسواد د دادهها از آمار توصيفى (فراوانى، ميانگين و انحراف معيار) و از آمار

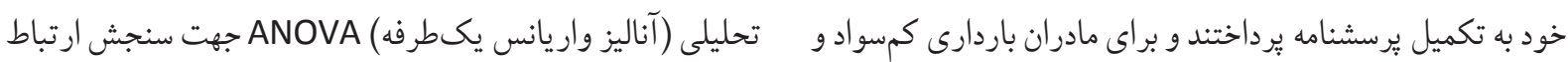

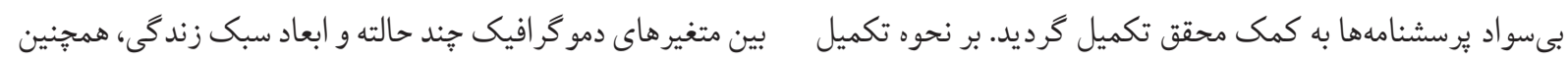

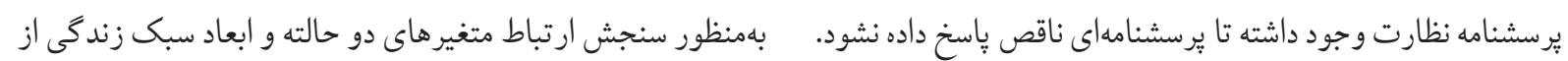

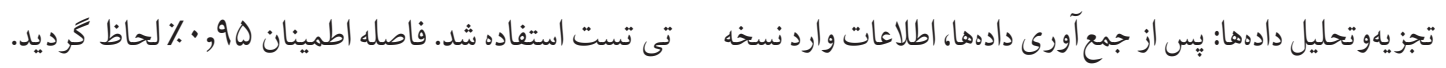

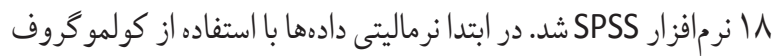

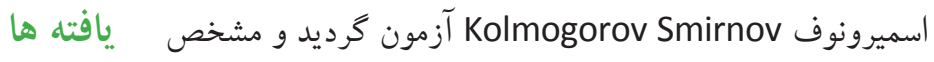

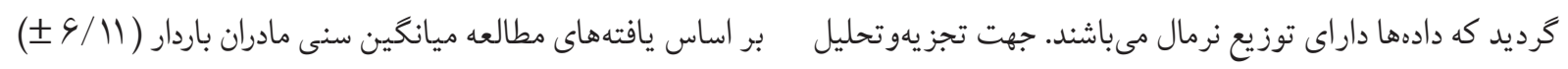




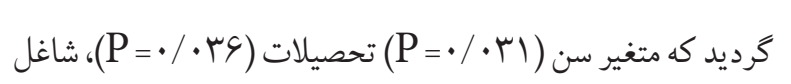

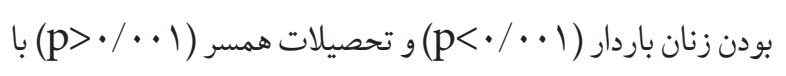

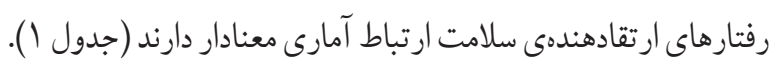

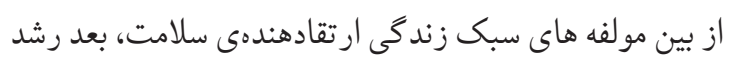

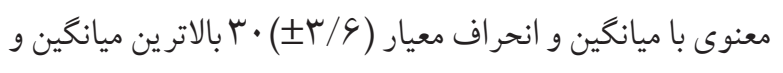

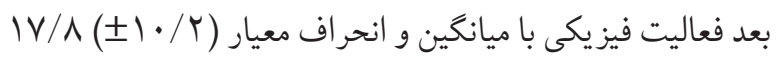
يا يين ترين ميانخين را به خود اختصاص داده است. اطلاعات بيشتر در جدول r بابلمشاهده است.

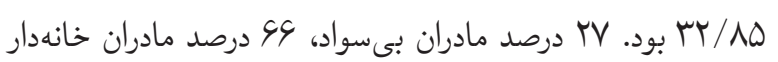
بودند. تحصيلات همسر در مقطع دبيرستان بيشترين فراوانى را ( Fl/V) فراوانى را داشت. ازنظر فراوانى شاخص توده بدنى رنج اضافهوزن

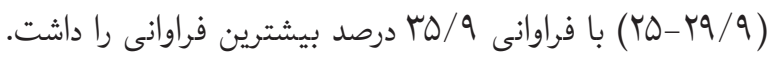

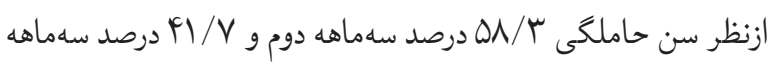

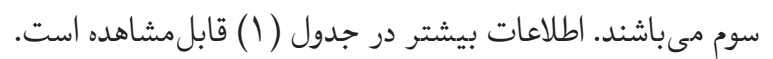

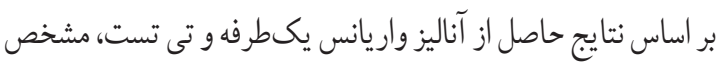

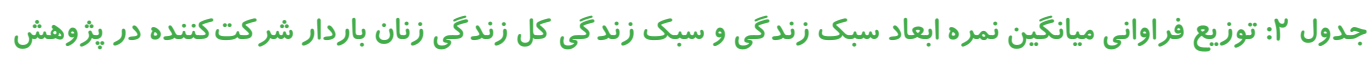

\begin{tabular}{|c|c|c|c|}
\hline انحراف معيار & ميانغين & متغير ها & \\
\hline $1 \cdot / r$ & $I V / \Lambda$. & فعاليت فيزيكى & \multirow{6}{*}{ ابعاد سبك زندگى } \\
\hline r/99 & rS/VO & تغذيه & \\
\hline$r / F V$ & rN/V. & ارتباطات & \\
\hline$r / s q$ & $r \cdot / \cdot \Delta$ & رشد روحى و معنوى & \\
\hline$F / F V$ & $r \mu / \mu$. & مديريت استرس & \\
\hline$p / 9 r$ & $r \Delta / \cdot \Delta$ & مسئوليتيذيرى & \\
\hline$T Y / Y F$ & $10 F / 9$ & سبك زندگى كل & \\
\hline
\end{tabular}

بعد مديريت استرس با متغيرهاى تحصيلات و شاغل بودن زنان

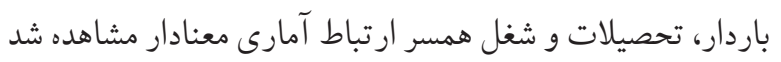
(جدول r) ( $)(\mathrm{p}<\cdot / \cdot 0)$

\section{بحث}

سلامت و ويشرفت هر جامعه تا حد زيادى بر سلامت زنان استوار

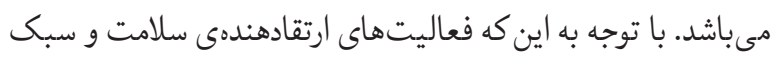

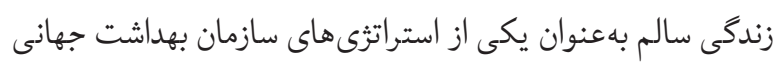

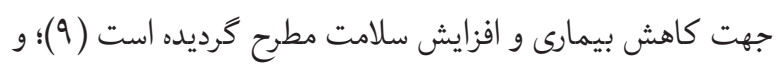
با توجه به اهميت اين نوع رفتارها بر سلامت زنان باردار و فرزندان

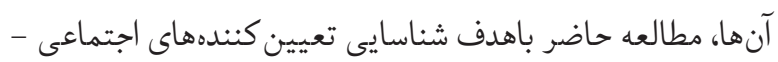
اقتصادى موثر بر سبك زندگى زنان باردار انجام يذيرفت. در مطالعه تهيد

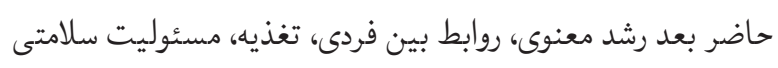
، مديريت استرس و فعاليت فيزيكى به ترتيب بيشترين تا كمترين
نتايج حاصل از تعيين رابطهى بين متغيرهاى مو ردمطالعه با نمرهى ابعاد سبك زندگى ارتقادهندهى سلامت نشان داد كه بعد فعاليت

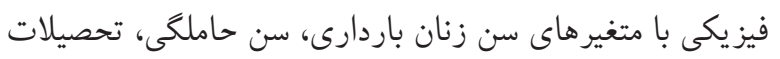

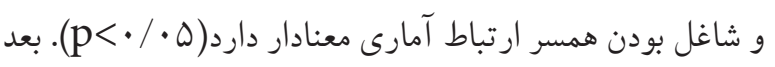

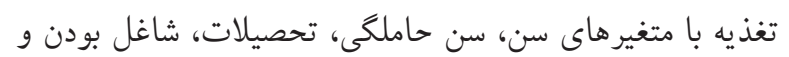

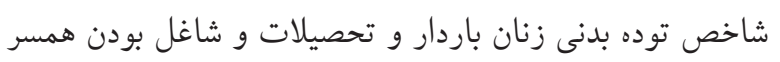

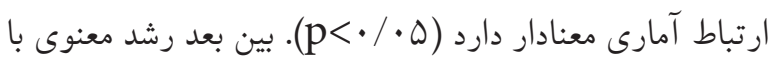

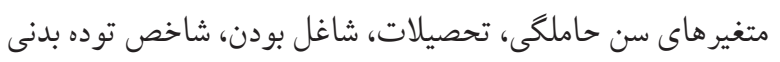
زنان باردار، تحصيلات و شاغل بودن همسر ارتباط آمارى معنادار

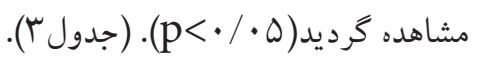

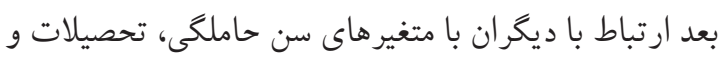

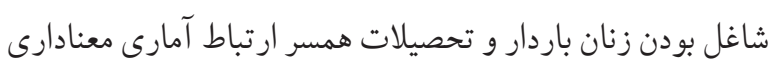

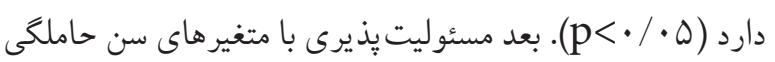

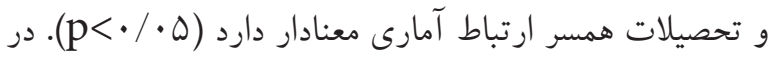




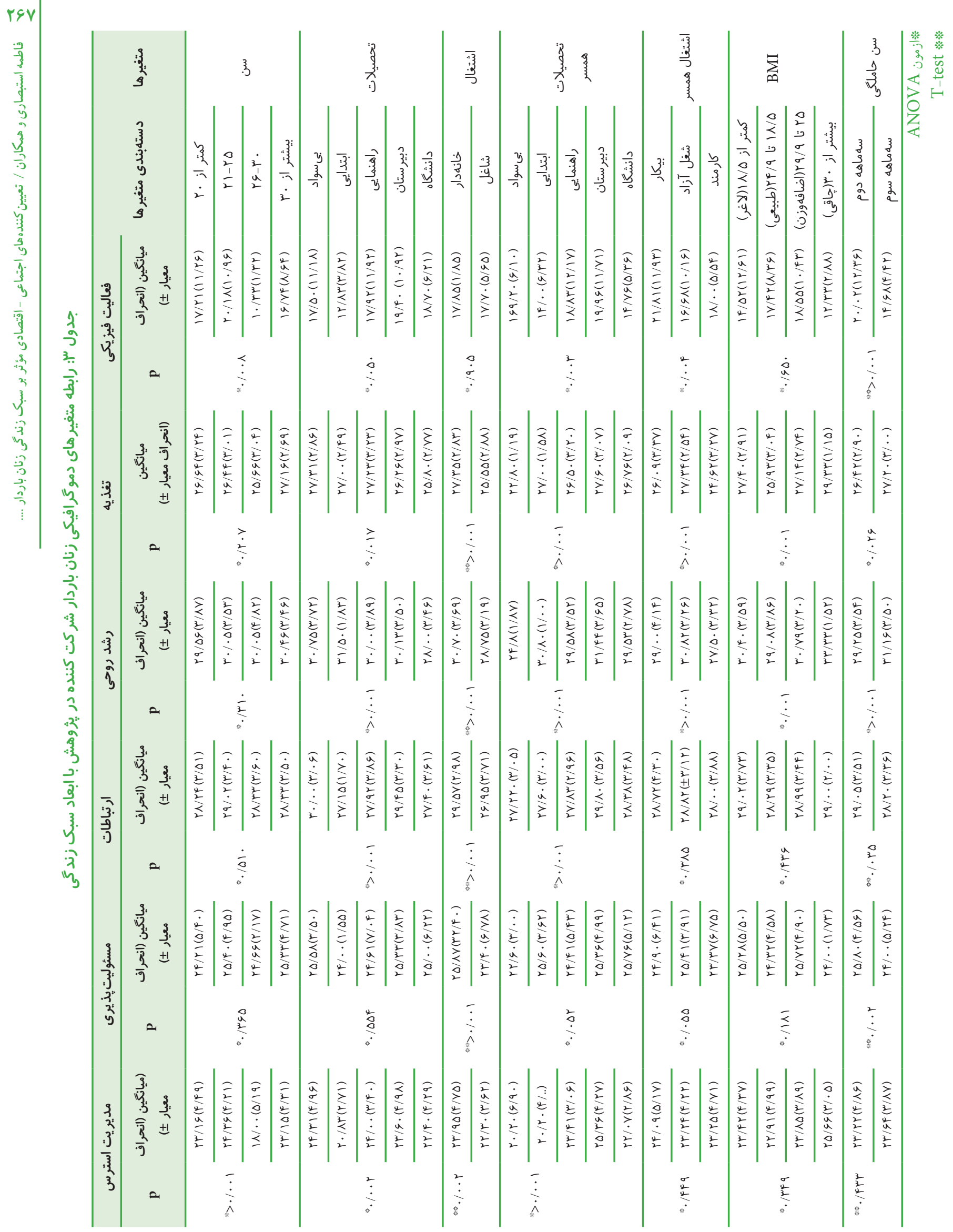


استرس، تجكونكى برقرارى ارتباط با ديكر ان و مر اقبتهاى دوران

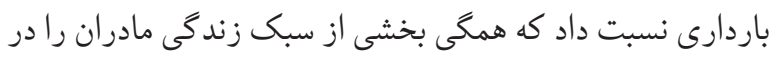

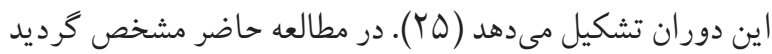

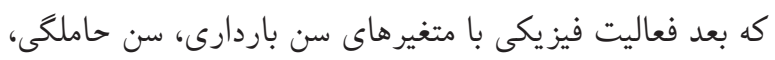

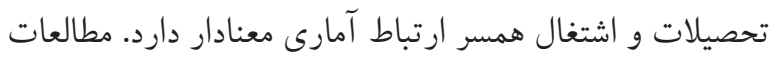
تاييد كردهاند كه انجام فعاليت فيزيكى منظم و شر كت در كلاسها

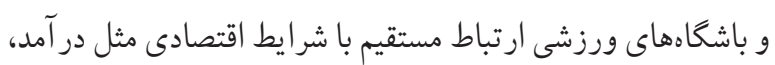
شغل و همجنين موقعيت اجتماعى افراد دارد (1) در مطالعه حاضر بعد روابط بين فردى ميانكين نسبتا كمى داشته است. ارتباط با ديكران بهمنظور داشتن حس صميمت و نزديكى بردي از طريق ارتباطات كلامى و غير كلامى براى سهيم كردن انديشها

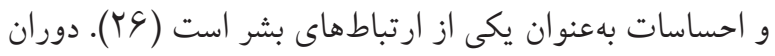

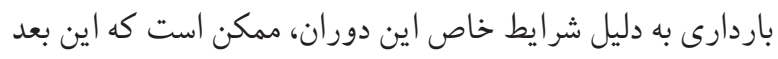

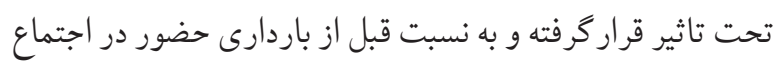

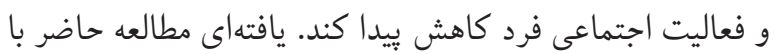

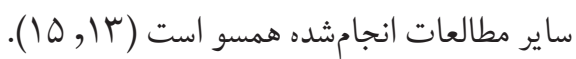
همجِنين در اين مطالعه مشخصشده است كه بعد ارتباط با ديكران با متغيرهاى سن حاملكى، تحصيلات و اشتغال زنان باردار و تحصيلات همسر ارتباط آمارى معنادار دارد. مطالعات نشان داده

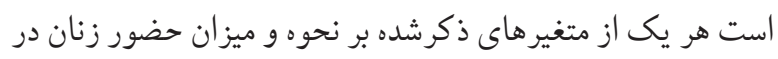

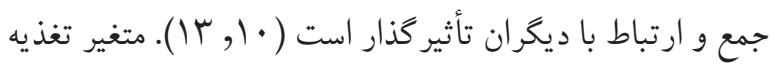

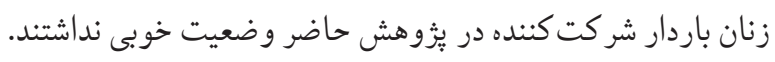

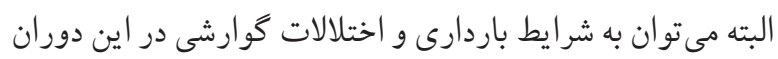
مرتبط دانست؛ كه اين يافته با ساير مطالعات انجامشده نيز همسو

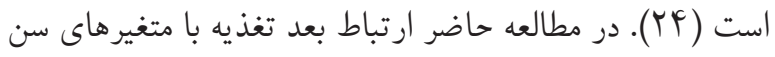
مادر، سن حاملكى، شاخص توده بدنى، تحصيلات و اشتغال زنان آنان

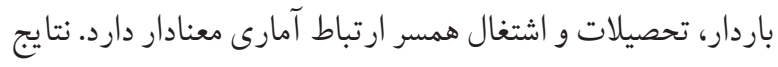

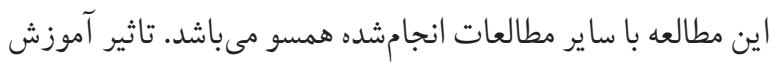

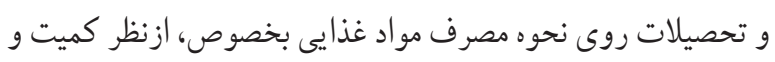
كيفيت رانمىتوان انكار كرد (r|). بعد تغذيه شامل انتخاب آكاهانه ميزان صحيح كروههاى غذايى و رثيم سالم بر اساس راهنماى هرم
ميانكين نمره را به خود اختصاص داده بودند. كسب ميانكين بيشتر

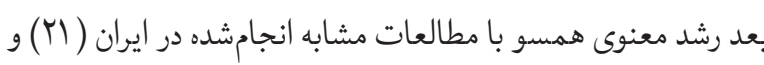
ساير كشورها (9) است. رشد معنويت و خود شكوفايى شامل داشتن حس هدف و مفهوم از يك سرى اهداف واقعى و حس ارتباط داشتن

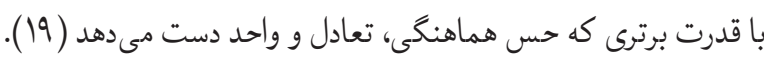
مطالعات نشان داده است كه شكل گيرى حس مادرانه و احساس مولد نداند بودن در دوران باردارى، سبب تقويت حس معنويت مى كردد. اين امر موجب شكل كرفتن و تقويت احساساتى مثل نزديكى به خالق هستى و معبود مى كردد و سبب رشد و تقويت معنويت مى كَردد (T) (T). بعد رشد روحى با متغيرهاى سن حاملكى، تحصيلات، اشتغال و شاخص توده بدنى زنان باردار، تحصيلات و اشتغال همسر ارتباط

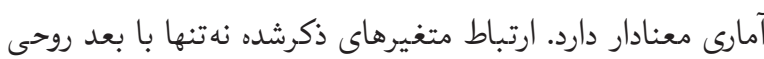
معنوى بلكه با سبك زندگى و كيفيت زندكى نيز هم در مطالعات

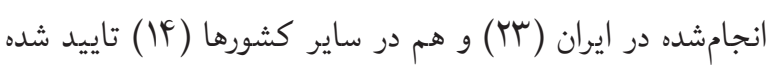

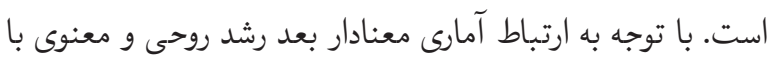
سبك زندگى، بهمنظور تغيير و ارتقاى سبك زندكى زنان باردار، بعد رشد روحى معنوى بايد موردتوجه قرار كيرد.

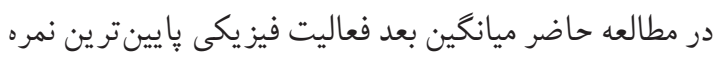
را به خود اختصاص داده بودند؛ كه بامطالعه مشابه انجامشده در ايران

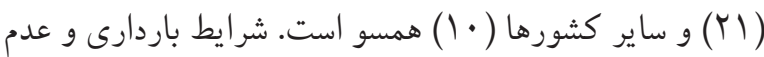

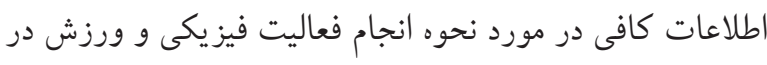

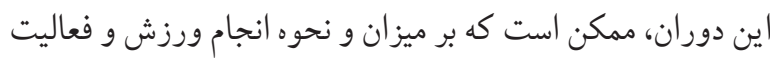

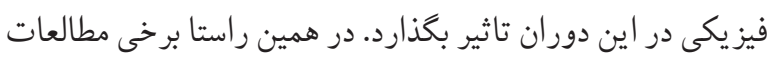
نشان داده است زنان تصور مى كنند كه انجام فعاليت فيز يكى ممكن دئن است كه بر سلامت جنين تاثير نامطلوب داشته و حتى منجر به ختم باردارى و زايمان زودرس گر ددد و حتى ممكن است كه منجر به ناهنجارىهاى جنينى گردد (• •). البته در مطالعهى انجامشده

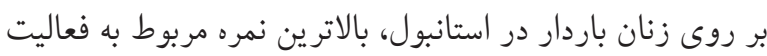

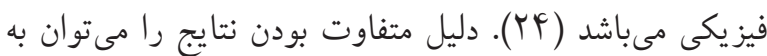
عواملى ازجمله فرهنگ و اعتقادات فرهنكى بخصوص در دوران

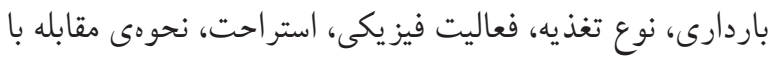


در مطالعه حاضر ميانگين نمره كل سبك زندگى زنان باردار در

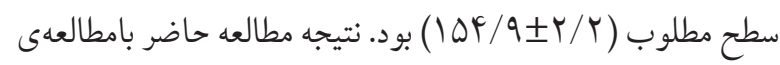
انجامشده بر روى زنان باردار در ساير جوامع (T) (I و مطالعه مشابه انجامشده در ايران (T) همسو است. در مطالعهى انجامشده در برد

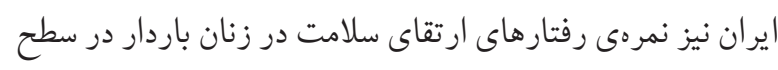

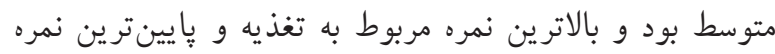

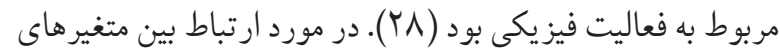

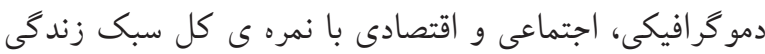
ارتقادهندهى سلامت مشخص گرديد كه بين سن، تحصيلات، اشتغال زنان باردار با رفتارهاى ارتقادهندهى سلامت رابطه آمارى معنادار

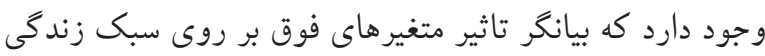
زنان باردار است؛ و هرجه مادر جوانتر و داراى تحصيلات بالاتر

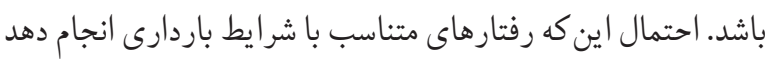
بيشتر است. موقعيت اقتصادى خوب بهواسطه شاغل بودن مادر هم

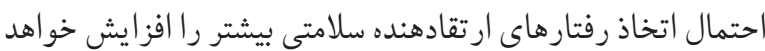
داد. نتايج مطالعه حاضر با نتايج مطالعات انجامشده در ايران و ساير

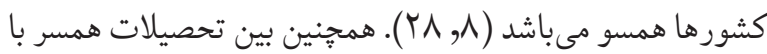
رفتارهاى ارتقادهندمى سلامت رابطه آمارى معنادار مشاهده گر ديد.

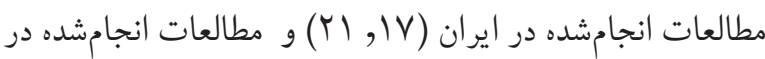

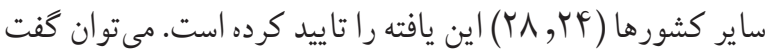
كه تحصيلات بالاتر همسر و بهواسطه آن كسب موقعيت شغلى بهتر آنها بهعنوان عامل تاثير گذار بر روى سبك زندكى و رفتارهاى

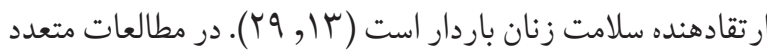

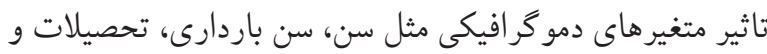

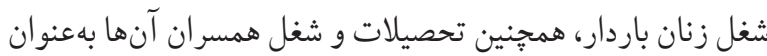
عوامل موثر بر سبك زندگى و رفتارهاى ارتقادهنده سلامتى تاييد

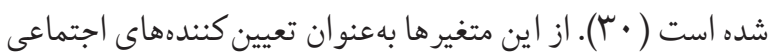

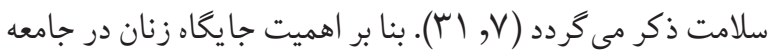
و نقش آنان در توسعهى همهجانبهى كشور، اطلاع از وضعيت

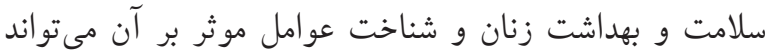
مبناى برنامهر يزىها و سياست گذارى هاى مناسب در جهت اصلاح
غذايى بهمنظور حفظ رفاه فردى مىباشد؛ و بهعنوان يك فاكتور مهم در دوران باردارى مىباشد كه سلامت مادر و جنين را تحت تاثير قرار مىدهد. همجنين مشخص شده است كه فاكتورهاى اقتصادى و اجتماعى و بخصوص درامد، شغل و تحصيلات روى اين فاكتور

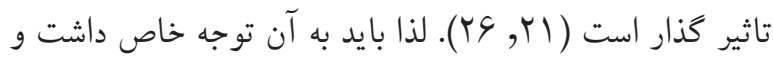

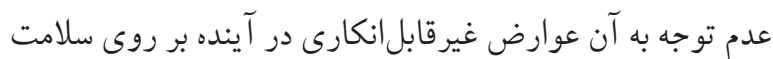
مادر و جنين خواهد كذاشت. بعد مسئوليت براى سلامتى شامل پاسخگو يیى يا ميزان مسئوليت

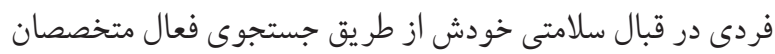

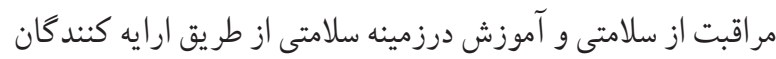
سلامتى مى باشد. در دوران باردارى به دليل شرايط باردارى و و تغييرات هورمونى ممكن است كه خانمهاى باردار حساستر و كم حوصله شوند (1/) يافتهاى مطالعه حاضر همسو با مطالعات

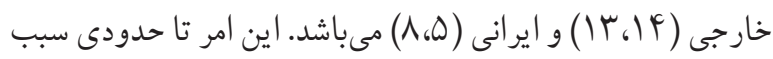

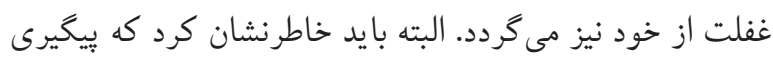

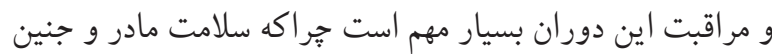
بايد بهعنوان يك امر مهم موردتوجه قرار گيرد.

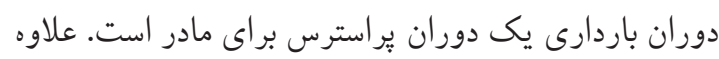

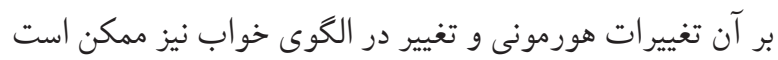

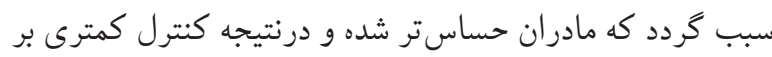
شرايط خود داشته باشند؛ كه اين امر روى نحوه و ميزان مديريت

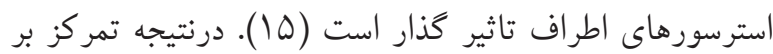
روى برنامه خواب، تسكين ساز و به همان اندازه استفاده از منابع در دسترس بر كنترل و كاهش تنشها در اين دوران حايز اهميت است. همجنين در مطالعه حاضر مشخص كرديد كه بعد مديريت استرس با متغيرهاى تحصيلات و اشتغال زنان باردار، تحصيلات

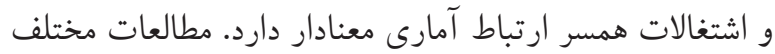

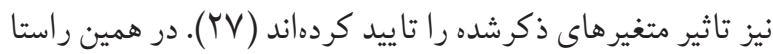
با توجه به تاثير استرس بر روى مادر و جنين توجه به اين بعد از

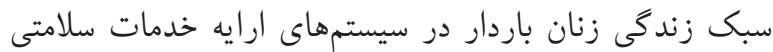

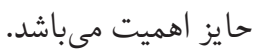




$$
\text { نتيجها، كيرى }
$$

با توجه به نتايج مطالعه حاضر مبنى بر وجود ارتباط آمارى معنىدار بين رفتارهاى ارتقادهندهى سلامت با متغيرهاى جمعيت شناختى، اجتماعى و اقتصادى، توجه به اين متغيرها بهعنوان تعيين كنندههاى سلامتى، از جانب سياست گذران و ارايه دهندگان خدمات سلامتى بهمنظور ارتقاى سلامت مادران باردار حايز اهميت مىباشد. نتايج مطالعه حاضر مطالعه مى تواند بهعنوان پيايهاى براى طراحى مداخلات مناسب جهت ارتقاى سبك زندگى و به دنبال آن كيفيت زندكى

$$
\text { مادران باردار مورداستفاده قرار كيرد }
$$$$
\text { تقد ير و تشكر }
$$

يُوهش حاضر مصوب شوراى يُزوهشى دانشگاه علوم يزشكى شهيد بهشتى با كد اخلاق IR.SBMU.RETECH.1397.27 مى باشد. از معاونت تحقيقات و فن آورى دانشخاه علوم يزشكى شهيد بهشتى براى حمايت مالى از اين مطالعه قدردانى مىشود. تضاد منافع: هيج گونه تضاد منافعى گزارش نشده است.

\section{Refrences}

1. Hill B, Kothe EJ, Currie S, Danby M, Lang AY, Bailey C, et al. A systematic mapping review of the associations between pregnancy intentions and health-related lifestyle behaviours or psychological wellbeing. Preventive Medicine Reports. 2019:100869.

2. Hamilton R, Barlow V, Qiu S, Debault J. Health Literacy and Health Behaviors in Adults. 2019.

3. Hussein ZF, Abbas AM. HEALTH BEHAVIOR CHANGE IN PREGNANT WOMEN WITH OBESITY. 2019.

4. Darkhor S, Estebsari F, Hosseini M, Charati JY, Vasli P. Effect of health promotion intervention on Nurses' healthy lifestyle and health-promoting behaviors: RCT study. Journal of Advanced Pharmacy Education and Research. 2018;8(1):108-14.

5. Abbaszadeh A, Hosseini M, Borhani F, Estabsari F, Shakeri $N$. The effects of self-care training on health-promoting behaviors of asthmatic patients. Ann Trop Med Public Health [serial online]. 2017;10(6):1785-91.

6. Estebsari F, Taghdisi MH, Rahimi Foroushani A, Eftekhar Ardebili H, Shojaeizadeh D. An educational program based on the successful aging approach on health-promoting behaviors in the elderly: a clinical trial study. Iranian Red Crescent medical journal. 2014;16(4):e16314.

7. Kiajamali M, Hosseini M, Estebsari F, Nasiri M, Ashktorab
وضعيت و ييشرفت زنان قرار كيرد؛ بنابر اين بايستى تاكيد نمود كه توليد و انجام يثزوهش هاى علمى و كارشناسانه در راستاى شناسايى همهجانبهى اين حوزه و رفع مشكلات و عوامل ايجاد كنندهى آن از نيازهاى اساسى كشور و جامعهى ما محسوب مىشود. ارتقاى سلامت در سطح جامعه، يك فر آيند يوياى توانمندسازى فرد در جهت كنترل سلامتى بر مبناى مداخلات ييشخير انهى سطح اول بوده. و بر تغييرات مثبت سبك زندگى تأكيد دارد، لذا توجه به رفتارهاى ارتقادهنده سلامتى در اين راستا حايز اهميت مىباشد.

از نقاط قوت يُزوهش حاضر بررسى رابطه متغيرهاى دمو گر افيكى، اجتماعى و اقتصادى با ابعاد رفتارهاى ارتقادهندهى سلامتى بوده است. از نقاط ضعف اين مطالعه مىتوان به محدود بودن بررسى نمونها در سهماهه دوم و سوم باردارى، به دليل عدم دسترسى به اطلاعات دقيق مربوط به سهماهه اول باردارى بود؛ بنابراين توصيه مى گردد كه براى بررسى سبك زندكى در صورت امكان از همان اوايل

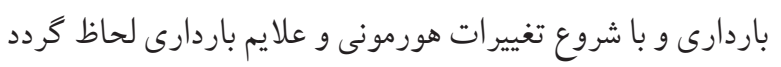

T, Abdi A, et al. Correlation between social support, selfefficacy and health-promoting behavior in hemodialysis patients hospitalized in Karaj in 2015 Electronic Physician. 2017;9(7):4820-7.

8. Bahabadi FJ, Estebsari F, Rohani C, Kandi ZRK, Sefidkar R, Mostafaei D. Predictors of health-promoting lifestyle in pregnant women based on Pender's health promotion model. International Journal of Women's Health. 2020;12:71.

9. Asci O, Rathfisch G. Effect of lifestyle interventions of pregnant women on their dietary habits, lifestyle behaviors, and weight gain: a randomized controlled trial. JOURNAL OF HEALTH POPULATION AND NUTRITION 2016;35(7)

10. Chan CW, Au Yeung E, Law BM. Effectiveness of Physical Activity Interventions on Pregnancy-Related Outcomes among Pregnant Women: A Systematic Review. International journal of environmental research and public health. 2019;16(10):1840.

11. Rahimian M, Mohammadi M, Mehry A, Rakhshani $\mathrm{MH}$. The predictors of physical activity among health volunteers based on pender's health promotion model Journal of Research \& Health 2018;8(4):308-12.

12. Krzepota J, Sadowska D, Biernat E. Relationships between 
Physical Activity and Quality of Life in Pregnant Women in the Second and Third Trimester. International Journal of Environmental Research and Public Health. 2018;15(2745).

13. Hamzehgardeshi Z, Gelehkolaee Keshvar S, Kardan Soraky M. Health-promoting Lifestyles and Related Factors in Pregnant Women. Internal Medicine and Medical Investigation Journal 2018;3(4):12-7.

14. Kim J-a, Cho E-y. The effect of health promotion behavior of female college students on marriage and pregnancy recognition. The journal of the convergence on culture technology. 2018;4(1):85-93.

15. Kazemi AF, Hajian S, Ebrahimi-Mameghani M, Khob MK. The perspectives of pregnant women on healthpromoting behaviors: an integrative systematic review. INTERNATIONAL JOURNAL OF WOMENS HEALTH AND REPRODUCTION SCIENCES. 2018;6(2):97-105.

16. Lawan A, Awotidebe AW, Oyeyemi AL, Rufa i AA, Oyeyemi AY. Relationship between Physical Activity and Health Related Quality of Life among Pregnant Women African Journal of Reproductive Health September 2018;22(3):80.

17. Abedi P, Jorfi M, Afshari P. Evaluation of the Health Promotion Lifestyle and its Related Factors in Reproductive Aged Women in Ahvaz, Iran. Community Health journal 2015;9(1):68-74.

18. Estebsari F, Dastoorpoor M, Mostafaei D, Khanjani N, Khalifehkandi ZR, Foroushani AR, et al. Design and implementation of an empowerment model to prevent elder abuse: a randomized controlled trial. Clinical interventions in aging. 2018;13:669-79.

19. Rahimi Foroushani A, Estebsari F, Mostafaei D, Eftekhar Ardebili H, Shojaeizadeh D, Dastoorpour M, et al. The effect of health promoting intervention on healthy lifestyle and social support in elders: a clinical trial study. Iranian Red Crescent medical journal. 2014;16(8):e18399.

20. Taghdisi $\mathrm{MH}$, Estebsari F, Rahimi Foroushani A, Eftekhar Ardebili $H$, Shojaeizadeh D, Dastoorpoor M, et al. The educational program based on the successful aging approach onelders health-promoting behaviors: a clinical trial study. RaziJournal ofMedicalSciences 2014;21(125):25-36.

21. Hassan M, Mohammad A-J, BabazadehTwohid, ShirzadiShayes-teh, Younes M, Pershang S-S, et al. Health Promoting Behaviors in Pregnant Women Admitted to the Prenatal Care Unit of Imam Khomeini Hospital of Saqqez. Journal of Education and Community Health. 2015;1(4):58-65.
22. Tork Zahrani S, Haji Rafiei E, Mohamad Khani Shahri L, Alavi Majd H. Investigation of Maternal- Fetal Attachment Behaviors and Its Related Factors in Pregnant Women, Qazvin in 2015. The Journal of Qazvin University of Medical Sciences. 2019;23(1):26-37.

23. Taghdisi $\mathrm{MH}$, Estebsari F, Rahimi Foroushani A, Eftekhar Ardebili H, Shojaeizadeh D, Dastoorpoor M, et al. The educational program based on the successful aging approach in elders health-promoting behaviors: A clinical trial study. Razi Journal of Medical Sciences. 2014;21(125):26-36.

24. Onat G, Aba YA. Health-promoting lifestyles and related factors among pregnant women Turk Journal Public Health 2014;12(2):69-79.

25. Mirghafourvand $M$, Baheiraei A, Nedjat S, Mohammadi E, Mohammad-alizadeh Charandabi S, Majdzadeh R. A population-based study of health-promoting behaviors and their predictors in Iranian women of reproductive age. Health Promotion International. 2014;30(3):586-94.

26. Esperat C, Feng D, Zhang Y, Owen D. Health Behaviors of Low-Income Pregnant Minority Women Western Journal of Nursing Research 2015;29(3):284-300.

27. Momeni Javid F, Simbar M, Dolatian M, Alavi Majd H. Comparison of Pregnancy Self-Care, Perceived Social Support and Perceived Stress of Women with Gestational Diabetes and Healthy Pregnant Women Iranian Journal of Endocrinology and Metabolism (IJEM). 2014;16(3):15664.

28. Kavlak O, Atan SU, Sirin A, Sen E, Guneri SE, Dag HY. Pregnant Turkish women with low income: Their anxiety, health-promoting lifestyles, and related factors. International Journal of Nursing Practice. 2015;21:923-32.

29. P A, M J, P A. Evaluation of the Health Promotion Lifestyle and its Related Factors in Reproductive Aged Women in Ahvaz, Iran. Community Health journal. 2017;9(1):68-74.

30. Calou CGP, de Oliveira MF, Carvalho FHC, Soares P, Bezerra RA, de Lima SKM, et al. Maternal predictors related to quality of life in pregnant women in the Northeast of Brazil. Health and quality of life outcomes. 2018;16(1):109.

31. Baheiraei A, Bakouei F, Mohammadi E, Montazeri A, Hosseni M. The Social Determinants of Health in Association with Women's Health Status of Reproductive Age: A Population-Based Study. Iranian journal of public health. 2015;44(1):119-29. 